Chapter 7

\title{
Vasculitis and Vasculopathy in Rheumatic Diseases
}

\author{
Mislav Radić and Josipa Radić \\ Additional information is available at the end of the chapter \\ http://dx.doi.org/10.5772/55056
}

\section{Introduction}

Vessels and the vascular endothelium are involved in the pathogenesis of inflammatory rheumatic diseases a family of related disorders that include rheumatoid arthritis (RA), systemic lupus erythematosus (SLE) and systemic sclerosis (SSc). In these conditions vascular involvement is very important. This chapter aims to give an overview of the prevalence of the different forms of vasculopathy/vasculitis that can be encountered in the RA, SLE and SSc patients, describe their pathogenesis, and address their impact on disease severity and outcome. All of these rheumatic diseases involve some level of underlying vasculitis.

SSc is a connective tissue disease characterized by fibrosis and vasculopathy involving multiple organ systems. Many clinical complications of SSc are due to dysfunction of vascular beds throughout the body. Involvement of the microvasculature leads to cutaneous and mucosal telangiectasias, digital ulcers, and tissue ischemia. If medium-sized blood vessels are involved, manifestations include gangrene, digital loss, renal crisis, and pulmonary arterial hypertension. While occlusive vasculopathy is a well-recognized feature of SSc, less is known about the occurrence and the consequences of frank vascular inflammation. Albeit rare, typical vasculitis with inflammatory infiltrates damaging blood vessels has been reported in patients with systemic sclerosis. The distinction between SSc vasculopathy and SSc-associated vasculitis can be difficult to make based on clinical presentation alone, but knowledge of the underlying pathogenesis and histopathology can be very helpful. In the current pathogenic model of SSc, a vascular injury of unknown cause leads to endothelial apoptosis and initiates the process of SSc vasculopathy. Continuous endothelial dysfunction likely contributes to activation of adventitial fibroblasts with resultant intimal proliferation, eventual luminal narrowing, and tissue hypoxia. Histopathology of SSc vasculopathy reflects the underlying pathogenesis, with myofibroblast proliferation and matrix deposit in the subendothelial layer leading to obliterative thickening of vessel walls. Inflammatory infiltrates are absent, and the internal elastic lamina remains intact. In contrast to vasculopathy, concurrent vasculitis in SSc 
shows histopathologic evidence of inflammation, with presence of mononuclear infiltrates and destruction of the vascular wall. However, vasculitis is known to occur even in the setting of a disease predisposing towards vasculopathy, and histology is required to distinguish the two pathogenic processes.

SLE is a connective tissue autoimmune disease, where vasculopathy is one of the typical symptoms. It is reported in $10-40 \%$ of patients. It occurs more often in women $(80 \%)$ than in men and may precede the development of a full-blown SLE. The differentiation of the type of vascular complications is very difficult, sometimes impossible, and requires an in-depth immune, histopathologic and imaging diagnostic approaches, and extensive clinical experience. It may play a key role in the choice of treatment strategy and prediction of the patient prognosis. Therefore, the awareness of the etiology, pathophysiology, the clinical and histopathogical setting, and SLE associated vascular complications is of great clinical significance. Vascular lesions in SLE are commonly known as the lupus vasculopathy; a typical lupus vasculitis with inflammatory and vascular wall necrosis and a thrombus in the lumen of affected artery occurs less often. SLE-associated vasculitis may present different clinical courses. The broad spectrum of symptoms includes mild forms affecting only cutaneous vessels, and also severe, catastrophic forms, with organ complications development, and vasculitis within the internal organs. Lupus vasculopathy is usually seen in cutaneous vessels, in renal glomeruli, coronary and brain vessels, the brain, lung alveoli and less often in the gastrointestinal tract. It has to be stressed that cutaneous lupus vasculopathy in systemic lupus erythematosus occurs most often, and is reported in $94 \%$ of patients with lupus vasculitis.

Systemic rheumatoid vasculitis is a multisystem autoimmune inflammatory condition of small and medium-sized vessels that typically affects a subset of patients with longstanding seropositive RA and alters the course and prognosis of the disease. Mortality rates are high, with significant morbidity. Systemic rheumatoid vasculitis refers to patients with rheumatoid arthritis, a chronic disease with painful inflammation of the joints, who also develop inflammatory disease in small and medium-sized blood vessels. The reason why systemic rheumatoid vasculitis develops in some RA patients and not others is not clear. Genetic factors may be involved. Viral infections and drug reactions have been suggested as causes of systemic rheumatoid vasculitis. The blood vessels most often involved are arteries that bring blood to the skin, nerves, and internal organs. Veins can also be involved. When systemic rheumatoid vasculitis involves the small arteries and veins that nourish the skin of the fingertips and skin around the nails, small pits in the fingertips or small sores causing pain and redness around the nails can occur. Involvement of somewhat larger arteries and veins of the skin can cause a painful red rash that often involves the legs. If the skin is very inflamed, ulcers can occur and infection becomes a complicating risk. Systemic rheumatoid vasculitis that injures the nerves can cause loss of sensation, numbness and tingling, or potentially weakness or loss of function of the hands and/or feet. The rare systemic rheumatoid vasculitis of larger arteries can cause complete absence of blood flow to tissue sites supplied by the affected vessel (termed occlusion, resulting in infarction), which can cause gangrene of fingers or toes, stomach pain, cough, chest pain, heart attack, and/or a stroke if the brain is involved. This form of systemic rheumatoid vasculitis can also be accompanied by general symptoms such as fever, loss of appetite, weight 
loss, and loss of energy. Higher titers of rheumatoid factors, antibodies to cyclic citrullinated peptides (anti CCP), and circulating immune complexes with lower C4 levels are detected in the sera of patients with RA and vasculitis, compared with patients with RA only. Deposition of rheumatoid factor-containing immune complexes likely contributes to vessel inflammation and damage through binding to cell surface Fc receptors, activation of the complement cascade, and release of proinflammatory cytokines.

\section{Systemic sclerosis (SSc)}

\subsection{SSc vasculopathy}

SSc is a connective tissue disease characterized by fibrosis and vasculopathy involving multiple organ systems. Classification into diffuse or limited cutaneous forms depends on the extent of skin thickening, with the former affecting areas proximal to the elbows or knees, and the latter limited to the face and distal extremities [1]. Systemic sclerosis (scleroderma) has two very different subsets: limited scleroderma and diffuse scleroderma. These can be identified by differences in clinical findings and by the temporal relationship to vasospasm. Limited scleroderma is so named because skin involvement is limited to the hands and face. Limited SSc is characterized by calcinosis, Raynaud's phenomenon, esophageal dysmotility, sclerodactyly, and telangiectasia (CREST syndrome). The most common cause of death in limited scleroderma is pulmonary hypertension or pulmonary fibrosis. Because Raynaud's phenomenon is a near universal prodrome, there are long-standing suggestions that the initial event in limited SSc may affect the vasculature [2]. Even in localized SSc, which has fewer systemic features, Raynaud's progresses to peripheral ischemia with digital ulceration and loss of fingers [3]. Although the vasospasm associated with Raynaud's phenomenon may be prodromal, it is not itself a sufficient cause of the disease because symptoms of vasospasm can precede diagnosis of limited SSc by many years, and the incidence of SSc in the population of people with Raynaud's phenomenon is very low [4]. Diffuse SSc appears with a much wider extent of skin involvement. Patients with diffuse SSc are prone to kidney crisis and pulmonary fibrosis. These patients develop Raynaud's phenomenon within 1 year of onset of symptoms but they tend to not have it as a prodrome. Both limited and diffuse SSc patients have ischemic changes in their digits (80\%-95\% have Raynaud's phenomenon), some with ulcers, gangrene, and loss of fingers [3]. Many clinical complications of SSc are due to dysfunction of vascular beds throughout the body. Involvement of the microvasculature leads to cutaneous and mucosal telangiectasias, digital ulcers, and tissue ischemia. If medium-sized blood vessels are involved, manifestations include gangrene, digital loss, renal crisis, and pulmonary arterial hypertension [5]. While occlusive vasculopathy is a well-recognized feature of SSc, less is known about the occurrence and the consequences of frank vascular inflammation. The distinction between SSc vasculopathy and vasculitis can be difficult to make based on clinical presentation alone, but knowledge of the underlying pathogenesis and histopathology can be very helpful. In the current pathogenic model of SSc, a vascular injury of unknown cause leads to endothelial apoptosis and initiates the process of SSc vasculopathy. Autoantibodies, reperfusion injury, infection, and defects in vascular repair have all been implicated as possible 
triggers [6]. Increased levels of endothelial cells in the circulation have been cited as evidence that the intactness of the vascular lining is jeopardized [6, 7]. Subsequent endothelial dysfunction results in the imbalance of vasoactive factors: decreased levels of vasodilators such as endothelial nitric oxide synthase and prostacyclin syntheses, as well as increased levels of the vasoconstrictor endothelin-1 and vascular endothelial growth factor [8, 9]. Continuous endothelial dysfunction likely contributes to activation of adventitial fibroblasts with resultant intimal proliferation, eventual luminal narrowing, and tissue hypoxia [7, 10]. Intimal hyperplasia, or more correctly the formation of a neointima, is a common response to arterial injury, and it is a characteristic feature of the arteries in SSc. The best evidence for intimal hyperplasia in SSc is found in a remarkable autopsy series reported by D'Angelo et al. [11] that is summarized in Table 1.

\begin{tabular}{cc}
\hline System & Pathology \\
\hline Pulmonary & $\begin{array}{c}\text { interstitial fibrosis and arterial thickening } \\
\text { fibrotic pleuritis }\end{array}$ \\
\hline Coronary & $\begin{array}{c}\text { myocardial fibrosis } \\
\text { arteriolar concentric intimal thickening } \\
\text { pericarditis fibrous and adhesive }\end{array}$ \\
\hline Gastrointestinal & $\begin{array}{c}\text { esophageal atrophy and fibrosis } \\
\text { lesions of reflux }\end{array}$ \\
Renal & $\begin{array}{c}\text { small intestine atrophy and fibrosis } \\
\text { large intestine atrophy and fibrosis }\end{array}$ \\
\hline Skeletal muscle & artery hyperplasia and bone marrow \\
& thickening, fibrinoid necrosis \\
\hline Arterioles & atrophy \\
& round cell myositis \\
\hline
\end{tabular}

Table 1. Summary of vascular pathology findings in SSC

Characteristic vascular changes in scleroderma also occur at the capillary level. The change most studied in the clinical literature is at the level of the nail beds. Changes in the nailfold capillaries are one of the first signs in SSc [12]. Because these changes have only been described by nail bed microscopy, little is known about the mechanism of this change. However, the morphology seen in the scleroderma nail beds closely resembles changes seen when vascular endothelial growth factor (VEGF) is overexpressed locally [13], and nailfold changes appear to be associated with very high levels of circulating VEGF [14]. These abnormalities have led to speculation that endothelial death is a primary and ongoing process in SSc. Although there is evidence from in vitro studies that SSc serum may contain antiangiogenic or other agents 
that are toxic to endothelium, apoptotic change or even increased endothelial turnover has not been demonstrated in vivo $[15,16]$. Endothelin-1 (ET-1) is a prototypical endothelial cellderived product, and endothelial damage leads to increased production of ET-1. Since ET-1 is a vasoconstrictive agent, loss of normal vessel compliance and vasorelaxation may be induced by increased levels of ET-1. In addition, ET-1 promotes fibroblast synthesis of collagen [17]. ET-1 upregulates expression of adhesion molecules, which promote the homing of pathogenic leukocytes to the skin. Further, ET-1 can also induce myofibroblast differentiation in fibroblasts [18]. ET-1 can induce connective tissue growth factor (CTGF), and may mediate the induction of collagen synthesis by activation of CTGF [19]. Circulating ET-1 levels have been observed in patients with diffuse SSc with widespread fibrosis and those with limited SSc and hypertensive disease [20], suggesting that soluble ET-1 levels may be a marker of fibrosis and vascular damage. Thus, ET is suggested to significantly contribute to fibrogenesis, linking between vasculopathy, and fibrosis, and the blockade of ET signalling may lead to the reduction of fibrosis. In vitro, SSc fibroblasts synthesized increased amounts of ET-1, and further, bosentan reduced the contractile ability of the SSc fibroblasts [18]. Therefore, a blocking ET-1 might be expected as a benefit in reducing pulmonary fibrosis. Recently, bosentan is demonstrated to reduce the number of newly formation of digital ulcers associated with SSc [21]. Additionally, bosentan may reduce the sclerosis of the skin in a pilot study [22].

Nitric oxide (NO) is a strong vasodilator and inhibits the biochemical effect of ET-1. However, ET-1 induces inducible NO syntheses (iNOS) expression in endothelial cells [23], and iNOS expression is detected in the endothelial cells in the lesion skin of SSc [24]. So far, several reports have shown impaired NO production in SSc [24, 25], which may contribute to the vascular pathogenesis of the arteriolar intimal proliferation in SSc. Thus, an imbalance between vasoconstriction and vasodilatation can lead to ischemia-reperfusion injury, endothelial damage and subsequent increased collagen gene expression via hypoxia. Hypoxia induces ECM proteins in cultured fibroblasts, and vascular endothelial growth factor (VEGF) overexpression may be caused in response to chronic hypoxia condition [26].

Histopathology of SSc vasculopathy reflects the underlying pathogenesis, with myofibroblast proliferation and matrix deposit in the subendothelial layer leading to obliterate thickening of vessel walls. Inflammatory infiltrates are absent, and the internal elastic lamina remains intact [27].

In contrast to vasculopathy, concurrent vasculitis in SSc shows histopathologic evidence of inflammation, with presence of mononuclear infiltrates and destruction of the vascular wall. Notably, both vasculopathic and vasculitic changes were seen in five of nine (55\%) digital amputation specimens from SSc patients, emphasizing that small vessel vasculitis and stenosing vasculopathy may coexist[27]. Further support has come from autopsy studies of SSc patients, where $24 \%$ of 58 cases showed noninflammatory intimal proliferation in two or more organs, but $9 \%$ had features of inflammatory polyarteritis [11]. Thus, vasculitis is known to occur even in the setting of a disease predisposing towards vasculopathy, and histology is required to distinguish the two pathogenic processes. 


\subsection{Large-vessel vasculitis associated with SSc}

Giant cell arteritis is a common vasculitis of the elderly involving large- and medium-sized arteries, typically the temporal, ophthalmic, vertebral, and axillary arteries as well as the aorta. The American College of Rheumatology (ACR) criteria include at least three of the following: (1) onset at age 50, (2) new headache, (3) claudication of the jaw or tongue, (4) temporal artery tenderness to palpation or decreased pulsation, (5) ESR $50 \mathrm{~mm} / \mathrm{h}$, and (6) temporal artery biopsy showing vasculitis with mononuclear inflammatory infiltrate or granulomatous inflammation with presence of giant cells [28]. While giant cell arteritis is relatively common among the vasculitides, it has only been reported in three cases of concurrent SSc, all of which were women in their sixth decade with limited skin involvement [29-31].

Takayasu arteritis is a relatively rare large vessel vasculitis (incidence $0.4-2 /$ million/year) affecting mostly young women of Asian origin although the incidence among the middleaged with atherosclerosis has been rising $[32,33]$. The aorta and its main branches are typically involved. ACR diagnostic criteria include at least three of the following: (1) onset before age 40, (2) claudication of an extremity, (3) decreased brachial artery pulse, (4) $10 \mathrm{mmHg}$ in systolic blood pressure between the arms, (5) bruit over the subclavian arteries or aorta, and (6) stenosis/occlusion of the aorta, its major branches, or large arteries in proximal upper or lower extremities [34]. Similar to giant cell arteritis, the histopathology in Takayasu arteritis shows mononuclear infiltrates in the vessel wall, intimal thickening, and destruction of elastic laminas, giant cell formation, and expansion of the adventitial layer. Elastic lamina destruction can lead to aneurysm formation while transmural inflammation drives intimal proliferation, adventitial scarring, and vascular lumen narrowing. Four cases of Takayasu arteritis in the setting of SSc have been reported. As the overwhelming majority of patients with Takaysu arteritis are female, all four of these cases were women, with ages ranging from 29 to 68 [35-38]. Three of the patients had diffuse skin involvement of SSc.

\subsection{Medium- and small-vessel vasculitis associated with SSc}

Polyarteritis nodosa (PAN) is a necrotizing vasculitis affecting medium-sized vessels, with a constellation of clinical findings that reflect multiorgan involvement. It can be associated with hepatitis B viral infection. PAN can be distinguished from the small-vessel vasculitides such as microscopic polyangiitis by the absence of antineutrophil cytoplasmic antibodies. The ACR diagnostic criteria for PAN include at least three of the following: (1) weight loss $4 \mathrm{~kg}$, (2) livedo reticularis, (3) testicular pain or tenderness, (4) myalgias, weakness, or leg tenderness, (5) mono- or polyneuropathy, (6) hypertension, (7) elevated blood creatinine or urea, (8) serum hepatitis B antigen or antibody, (9) aneurysms or occlusions of visceral arteries, or (10) granulocytes on biopsy of small- or medium-sized arteries [39]. A recent retrospective study of 348 patients with PAN found general symptoms in $93.1 \%$, neurologic involvement in $79 \%$, and skin involvement in about 50\% [40]. Five-year relapse-free survival was $59.4 \%$ for nonhepatitis-B-associated PAN and 67\% for HBV-associated PAN. Only one case of PAN has been described in a 28-year-old woman with diffuse SSc, characterized by Raynaud's phenomenon and skin sclerosis over the hands, arms, and chest [41]. 
Primary angiitis of the central nervous system (PACNS) is a rare poorly characterized entity affecting small- and medium-sized vessels of the central nervous system (CNS) but not organs or vessels outside the CNS. In general, PACNS is distinguished from secondary CNS vasculitis with the exclusion of infections, malignancy, systemic vasculitis or connective tissue disease, or drug-induced vasculitis. Clinical presentations of PACNS include confusion, new onset headache, seizures, stroke or cerebral hemorrhage, and myelopathy [42]. The duration from symptom onset to diagnosis can range from 3 days to 3 years [43]. Multiple laboratory data abnormalities can occur but none is specific for the diagnosis, with ESR described to be normal in a number of cases. Characteristic changes on cerebral angiography include multifocal segmental stenosis, dilatation, or occlusion of small- and medium-sized leptomeningial and intracranial vessels as well as formation of collateral vessels. Further supportive evidence can be obtained from leptomeningeal or parenchymal biopsies, which are specific but not sensitive for vasculitis given the focal segmental nature of the disease; therefore, a negative biopsy does not rule out the diagnosis. Histology can show either granulomas in small vessel walls, lymphocytic infiltrates, or necrotizing vasculitis [43]. The rarity and heterogeneity complicate classification, diagnosis, and management. Calabrese and Mallek have proposed the following diagnostic criteria for PACNS: (1) recent onset of headache, confusion, or multifocal neurologic deficits, (2) cerebral angiographic changes suggestive of vasculitis, (3) exclusion of systemic disease or infection, and (4) leptomeningeal or parenchymal biopsy to confirm vasculitis and to exclude infection, malignancy, and noninflammatory vascular occlusive disease [44]. However, only one case of PACNS has been described in SSc [41].

\subsection{Mixed cryoglobulinemia and cryofibrinogenemiaassociated with SSc}

Mixed cryoglobulinemia is the presence of polyclonal immunoglobulins that precipitate in the serum with cold exposure, often secondary to a connective tissue disease such as systemic lupus erythematosus or Sjogren's syndrome. The presence of cryoglobulins (CGs) may be asymptomatic or may lead to manifestations of the cryoglobulinemic syndrome, including purpura, arthralgia, myalgia, glomerulonephritis, and peripheral neuropathy [45]. The diagnosis of the latter entails a combination of clinical presentation, laboratory testing showing the presence of circulating cryoglobulins, and histopathologic appearance such as leukocytoclastic vasculitis (most common). Similarly, cryofibrinogenemia is the presence of cold-induced precipitants in the plasma but not in the serum. Connective tissue diseases, malignancy, and infection have been known to be associated with this condition, which can be asymptomatic or can manifest as painful ulcers, purpura, or perniosis, reflecting possible underlying cold-induced thromboses, increased blood viscosity, or vascular reactivity. The diagnosis of clinically significant cryofibrinogenemia requires not only circulating cryofibrinogen (CF) but also clinical features and histopathologic evidence of small-vessel thrombosis and perivascular infiltrate [46]. For both mixed cryoglobulinemia and cryofibrinogenemia, treating the underlying disease (whether infection, connective tissue disease, or malignancy) can sometimes improve symptoms. Plasmapheresis and immunosuppression with glucocorticoids and/or cytotoxic therapy have also been used in severe disease although with unclear efficacy. 
Connective tissue diseases have been associated with the presence of both CG and CF, perhaps more so than CF alone [47]. In the few studies and reports involving SSc, these cold-induced precipitants do not appear to trigger symptoms. In one study, one out of 19 patients with both CG and CF carried the diagnosis of SSc [47]. In another study, 10 out of 20 SSc patients had the presence of polyclonal IgG and IgM cryoglobulins in the serum, but none exhibited clinical signs of cryoglobulinemic syndrome [48]. In one report of long-standing SSc with the presence of cryoglobulins (both IgG and $\operatorname{IgM}$ ), the patient presented with paresthesias, transient aphasia, vision changes, and delirium. Cerebral angiogram was normal, and electroencephalogram revealed generalized slowing of action potentials, and computed tomography of the extremities revealed calcinosis. While peripheral neuropathy can be a manifestation of mixed cryoglobulinemia, central nervous system involvement would be highly unusual; therefore it, is unclear whether the presence of cryoglobulins in this case is an incidental finding. Another man with long-standing SSc presented with sudden onset gangrene in the fingers and toes after cold exposure and was found to have very elevated cryofibrinogen [49].

\subsection{Behcet's disease associated with SSc}

Behcet's disease is characterized by recurrent oral aphthous ulcers and other systemic manifestations believed to be due to systemic vasculitis, including genital aphthous ulcers, ocular disease, skin involvement, gastrointestinal ulcers, neurologic disease, and arthritis. It is more common along the ancient Silk Road, with $0.11 \%$ prevalence in Turkey and $2.6 \%$ per 100,000 in Southern China [50]. Diagnosis is made based on clinical features including presence of recurrent oral aphthae plus two of the following without other systemic disease: (1) recurrent genital aphthae, (2) eye lesions including uveitis or retinal vasculitis, (3) skin lesions including erythema nodosum, pseudovasculitis, papulopustular lesions, or acneiform nodules, or (4) positive pathergy test [51]. Treatment for mucocutaneous and joint disease includes colchicine (mixed results), glucocorticoids, and other immunosuppressives such as azathioprine. More serious disease with internal organ involvement has been treated with cyclophosphamide and high-dose steroids. Overviewing the literature, only two cases of Behcet's disease with concurrent SSc have been reported [52, 53].

\subsection{Relapsing polychondritis associated with SSc}

Relapsing polychondritis (RPC) is an inflammatory disease of unknown etiology involving cartilagenous tissues in multiple organs, typically the ears, nose, eyes, respiratory tract, and joints. Vascular and neurologic complications have also been reported. Association with systemic vasculitis, connective tissue disease, or myelodysplastic syndrome occurs in up to one-third of the cases. The original diagnostic criteria by McAdam required three of six clinical manifestations: (1) bilateral auricular chondritis, (2) nonerosive seronegative polyarthritis, (3) nasal chondritis, (4) respiratory tract chondritis, (5) ocular inflammation, or (6) cochlear and/or vestibular dysfunction [54]. The criteria were later modified to include the presence of three or more of the above, one clinical manifestation with corroborating histology, or chondritis at more than two sites responsive to steroids or diamino-diphenyl sulfone [55]. Only one case of RPC has been reported in association with SSc [56] 


\subsection{ANCA-associated vasculitis (AAV) in SSc patients}

The spectrum of necrotizing small-vessel vasculitis known as ANCA-associated vasculitis (AAV) includes Wegener's granulomatosis (WG), microscopic polyangiitis (MPA), and ChurgStrauss syndrome (CSS). While formally classified as small-vessel vasculitis, AAV can involve medium-sized vessels. Cytoplasmic antineutrophil cytoplasmic antibodies (c-ANCAs) directed against proteinase 3 (PR3) are more commonly found in WGs whereas perinuclear ANCAs (p-ANCA) targeting myeloperoxidase (MPO) are more frequently seen in MPA and CSS. Variable organ involvement makes diagnosis a challenge, with alveolar hemorrhage and crescentic glomerulonephritis frequently occurring in WG and MPA, while polyneuropathy can be seen in ANCA-associated CSS [57]. Disease stage can range from localized without endorgan damage to severe generalized with organ failure. Of all the small vessel vasculitides, $\mathrm{AAV}$ is the most frequently reported in association with SSc, raising the question whether an overlap syndrome exists that combines features from both diseases. A study by Rho et al. found 31 reports containing 63 cases of AAV in SSc up to 1994 [58].

While lumen-occlusive vasculopathy is a prominent feature of SSc, frank vasculitis may also occur. Coexistent SSc and vasculitis have been reported for vessels of all sizes, either before or after SSc diagnosis, and in either SSc subtype (limited or diffuse).

\section{Systemic lupus erythematosus (SLE)}

\subsection{Vascular involvement in SLE}

SLE is a connective tissue autoimmune disease, where vasculopathy is one of the most typical symptoms [59]. Vascular involvement is frequent in SLE patients and represents the most frequent cause of death in established disease. In this context, vasculopathy can be directly aetiologically implicated in the pathogenesis of the disease, presenting as an acute/subacute manifestation of lupus (e.g., antiphospholipid syndrome (APS), lupus vasculitis). Besides overt vessel obstruction, vascular disease in lupus, especially when affecting medium- and smallsized vessels, may contain both vasculopathic and vasculitic pathophysiologic parameters.

Livedoid vasculopathy, a condition which can be observed in patients with systemic lupus erythematosus/antiphospholipid syndrome or specific forms of systemic vasculitis (mainly polyarteritis nodosa and cryoglobulinemia), is associated with chronic ulcerations of the lower extremities and characterized by uneven perfusion [60]. The pathogenesis of livedoid vasculopathy has not been fully elucidated, or rather, cannot be solely attributed to a particular mechanism, as both hypercoagulable states, as well as autoimmune diseases, appear to associate with and contribute to its development [61].

The typical histological findings show dermal blood vessel occlusion [62]. The histopathological findings of intravascular fibrin, segmental hyalinization, and endothelial proliferation clearly support the thrombotic parameter of its pathogenesis [63]. The presence of immunoreactants in the vessel wall and circulating immune complexes (such as rheumatoid factor) are in favor of its immunological component; the absence however of fibri- 
noid necrosis and inflammatory infiltration of the vessel wall differentiates livedoid vasculopathy from true vasculitides.

It is reported in $10-40 \%$ of patients. It occurs more often in women $(80 \%)$ than in men and may precede the development of a full-blown SLE [64]. Vascular lesions in SLE are commonly known as the lupus vasculopathy; a typical lupus vasculitis with inflammatory and vascular wall necrosis and a thrombus in the lumen of affected artery occurs less often [65-67]. However, the rate of thrombotic events is higher in patients with disease of recent onset, when compared to patients with other autoimmune diseases and remains so throughout the course of the disease [68]; in the LUMINA study, which included multiethnic SLE patients of recent diagnosis, age, damage accrual at enrolment, and antiphospholipid antibodies, as well as the use of higher dosages of glucocorticoids were associated with a shorter time interval to thrombotic events [69]. Appel et al. [66] provided an SLE vasculopathy classification including: non complicated vascular deposits of immune complexes, noninflammatory necrotic vasculopathy, thrombotic microangiopathy and true lupus vasculitis. Of all lupus vasculitis, cases more than $60 \%$ is leucocytoclastic inflammation, $30 \%$ is vasculitis with cryoglobulinemia, and systemic vasculitis resembling polyarteritis nodosa constitutes about $6 \%$ of SLE vasculitides patients [66, 70-72]. Other clinical syndromes of vasculopathy in patients from the discussed group include thrombocytopenia with thrombotic purpura, venous thrombosis, antiphospholipid syndrome and urticaria vasculitis, reported in 5\% of SLE patients [66]. The SLE associated vasculitis may present different clinical courses. The broad spectrum of symptoms includes mild forms affecting only cutaneous vessels, and also severe, catastrophic forms, with organ complications development, and vasculitis within the internal organs [73, 74]. Lupus vasculitis is usually seen in cutaneous vessels, in renal glomeruli, coronary and brain vessels, the brain, lung alveoli and less often in the gastrointestinal tract [59]. It has to be stressed that cutaneous lupus vasculopathy in SLE occurs most often, and is reported in 94\% of patients with lupus vasculitis $[75,76]$. Mild forms are characterized by purpura, urticaria lesions or bullous lesions of extremities, and livedo reticularis on the trunk.

It has been demonstrated that internal organ vessels are affected in $18 \%$ of SLE vasculitis patients. Renal vasculitis takes the shape of focal segmental glomerulitis with development of fibrinoid necrosis [59]. Lung vasculitis takes the form of necrotic alveolar capillaritis predisposing to pulmonary hemorrhage [59]. Brain vasculitis occurs only in about $10 \%$ of SLE patients, and associated clinical symptoms are very variable; from a mild cognitive dysfunction to severe psychosis and convulsions, local ischemia and strokes [59, 77]. The peripheral nervous system may also be affected by lupus vasculopathy leading to multifocal inflammatory mononeuropathies [59]. Mesothelium vasculitis may also occur and lead to gastrointestinal hemorrhage or perforation [59]

\subsection{Antiphospholipid syndrome}

The clinical APS, an autoimmune syndrome usually developing in the context of SLE, is a condition defined as a predisposition for arterial and/or venous thromboses and/or recurrent miscarriages or other obstetric emergencies (e.g., premature birth, preeclampsia) in association with hematologic abnormalities and specific antibodies targeted against phospholipid- 
binding plasma proteins [78]. It has been suggested that endothelial damage of whatever origin exposes endothelial cell phospholipids, which enables the adhesion of antibodies directed against phospholipids (aPL) [75]. The pathogenetic action mechanisms of aPL antibodies are variable. When binding with membrane phospholipids aPL antibodies may inhibit reactions catalyzed by them in the coagulation cascade, for example through inhibition of $C$ and $S$ protein activation [79]. These antibodies may also activate endothelial cells thrombin formation [79]. The binding of aPL antibodies with platelet membrane phospholipids binding protein predisposes to platelet activation and adhesion, with consequent thrombus formation. These antibodies probably also participate in the complement system activation [79]. As a result, the aPL antibodies demonstrate proadhesive, proinflammatory and prothrombotic effects on endothelial cells [79].Thrombosis within the context of APS may occur even in histologically normal vessels. However, in the majority of aPL-positive patients, seropositivity per se does not suffice for the development of clinical events. Thrombotic events seem to occur more readily in SLE patients with coexistent atherosclerosis [80]. Recently, the presence of microangiopathy, defined as capillary microhemorhages, and diagnosed with the aid of capillaroscopy, has been proposed as an augmentary screening tool for aPL-seropositive patients who are prone to develop clinical thrombotic manifestations [81].

\subsection{Lupus vasculitis}

Distinction of inflammatory lupus vasculitis from APS, which may present with similar clinical manifestations, is of major significance in terms of clinical management. Inflammatory vascular disease is triggered by the in situ formation, or the deposition, of immune complexes within the vessel wall.

Vasculitis may manifest in as high as 56\% of SLE patients throughout their life, in contrast to antiphospholipid syndrome which has a prevalence of $15 \%$. Patients with vasculitis are mainly male and tend to be of younger age [82]. Antibodies against endothelial cells have been identified as a major endothelial cell cytotoxic effector and have been implicated in the pathogenesis of several connective tissue diseases, predominantly vasculitides [83]. More than $80 \%$ of systemic lupus erythematosus patients are positive for antiendothelial cell antibodies (AECAs) [84]. Other forms of SLE-related vasculitis include drug-induced vasculitis [85] and infection-induced vasculitis [86] either through direct compromise of the vascular wall by pathogens, or through antigen-induced autoimmune and inflammatory processes. Some drugs may play a role in the induction of inflammatory vascular lesions in SLE. The drug molecule may act as a hapten, which as a result of autoantigen binding alters the antigen properties. Several SLE inducing drugs are listed below: penicillins, allopurinol, thiazides, pyrazolones, retinoids, streptokinase, cytokines, monoclonal antibodies, chinolons, hydantoin, carbamazepine and other anticonvulsants $[59,87]$. Vasculitis may be a result of direct attack of microorganisms on the blood vessel wall or may be caused by infected thrombotic mass [74]. Hepatitis C virus may take part in vasculitis development, with the cryoglobulin presence [88]]. There is an unexplained relationship between blood cryoglobulins and hepatitis $C$ [74]. The following mechanisms leading to viral and bacterial vasculitis in SLE have been suggested: [1] the viruses directly attack the vascular wall inducing an inflammatory process, 
[2] some of them, as cytomegalovirus, may permeate and activate endothelial cells leading to vasculitis and [3] bacterial Staphylococcus antigens, as for example neutral phosphatase, may bind with basement membranes and adhere specifically to $\mathrm{IgG}$, which in turn induces an immune response and an inflammatory process.

\section{Rheumatoid arthritis (RA)}

RA is a chronic inflammatory systemic disorder which primarily involves the joint synovial membrane. The purpose of this chapter section is to describe the occurrence and pathophysiology of vasculitis and vasculopathy in RA.

\subsection{Rheumatoid vasculitis}

Rheumatoid vasculitis typically affects small and medium-size blood vessels. It is associated with high rates of premature mortality with up to $40 \%$ of patients dying by 5 years as well as significant morbidity due to both organ damage from vasculitis and consequences of the treatment $[89,90]$. Diagnostic criteria for systemic rheumatoid vasculitis were proposed in 1984 by Scott et al. [91], although the classification of RA-associated vasculitis remains poorly codified. It shares many characteristics with a classic polyarteritis nodosa and may affect peripheral nerves, causing mononeuritis multiplex, skin, gastrointestinal tract, and other organs, but it is not usually associated with the development of microaneurysms [92]. High levels of circulating immune complexes have been observed in patients with rheumatoid vasculitis [93], and in particular high serum levels of rheumatoid factor are often detected at the time of onset of vasculitis [94]. Deposition of immune complexes most likely contributes to small vessel inflammation and organ damage. Anti CCP levels also tend to be higher in patients with RA who have systemic vasculitis than in those who do not. Rheumatoid vasculitis has been reported in a substantial number of patients with RA [95]. It is more common in men and patients with longstanding disease [91]. The annual incidence of rheumatoid vasculitis in men to be 15.8 per million and in women, 9.4 per million [95]. Nevertheless, the 30-year incidence of vasculitis in patients with RA was estimated to be $3.6 \%$ [96].

Predictors of vasculitis in RA patients include clinical and generic factors (Table 2) [97-103]. Smoking, which is also a risk factor for development of RA in the general population [104], is associated with an increased risk of vasculitis among patients with RA [99, 100]. Rheumatoid nodules early during the disease predict the occurrence of systemic rheumatoid vasculitis [97, 98]. However, genetic predisposition toward developed RA, as HLA-DRB1-shared epitope genotypes is strongly associated with extraarticular disease manifestations such as rheumatoid vasculitis [101, 102]. In particular, double dose of RA-associated HLADRB1*04 alleles is associated with an increased risk of vasculitis [105]. Rheumatoid vasculitis is associated with an increased mortality as compared with that in patients with RA in general [89]. In particular, a poor survival has been observed after diagnosis of vasculitis-related neuropathy [106]. In such patients, a low serum level of complement factor C4 is a negative prognostic marker [90]. 
The increased mortality may be due to a high risk of cardiovascular comorbidity $[107,108]$ and severe infections [109].

\begin{tabular}{cc}
\hline Marker & Pathophysiological explanation \\
\hline Rheumatoid nodules & sign of microvascular extraarticular inflammation \\
\hline Smoking & vascular damage, immunomodulation \\
\hline HLA-DRB ${ }^{*}$ 04/04 double gene dose & selection and activation of T cells \\
\hline HLA-C*3 allele & activation of cytotoxic CD28null T cells \\
\hline KIR2DS2 allele & activation of cytotoxic CD28null T cells \\
\hline
\end{tabular}

$\mathrm{KIR}$, killer immunoglobulin-like receptors

Table 2. Predictors for vasculitis in RA patients

According to the data from the literature very little is known of what events trigger the development of vasculits in RA patients at a particular time point. This probably includes a number of different infectious agents and other immune exposures. For example, rare cases of rheumatoid vasculitis following influenza vaccination have been described [110].

\subsection{Clinical manifestations of rheumatoid vasculits}

Rheumatoid vasculitis often affects more than single organ. Patients may develop nailfold infarcts and leg ulcers. These patients may go on to have more widespread vascular disease but usually do not [111]. Cutaneous manifestations of rheumatoid vasculitis may present as digital digital infarcts, livedo, palpable purpura, bulla, ulcerations, painful nodules, or gangrene. Histologically, rheumatoid vasculitis involves blood vessels of the small arteries, and all layers of the vessel wall are infiltrated by neutrophils, lymphocytes, and plasma cells. Cutaneous manifestation of rheumatoid vasculitis is classified into three grades: severe, moderate, and mild. The severe type presents with digital gangrene, nail fold infarcts, large cutaneous ulcers; the moderate type presents with palpable purpura; and the mild type presents with nailfold telangiectasias with thromboses, minute digital ulcerations, petechiae, and livedo reticularis. Minor bleeding from the nail folds, finger pulp, and the edge of the nails results from digital infarcts (isolated nailfold vasculitis) [112]. RA patients who develop leg ulcers and digital ulcers should be more closely monitored, especially patients who have high titers of rheumatoid factor, positive anti CCPs, cryoglobulins, and low complements, as more ominous manifestations of RA are more likely to occur in these patients [113]. The diagnosis of leg ulcers in patients with RA is often associated with trivial trauma. There is often an underlying vasculitis, which promotes the lesion.

Systemic vasculitis in RA usually occurs in patients who have longstanding disease, generally of more than 10-year duration. Even so, it may occur at any time during the disease course, and, irrespective of when it occurs, it is associated with a poor prognosis. From a clinical standpoint, patients have more severe RA with destructive joint disease and other features of 
extraarticular disease [98]. Patients with Felty's syndrome are particularly prone to develop rheumatoid vasculitis. The appearance of rheumatoid vasculitis may be associated with a rise in acute-phase markers, including the sedimentation rate and C-reactive protein, together with longstanding thrombocytosis and anemia of chronic disease [98]. RA-associated vasculitis may involve any blood vessel bed in the body, including cerebral, mesenteric, and coronary arteries [114]. More severe features of rheumatoid vasculitis are frank infarctions of the digits and mononeuritis multiplex [113, 115]. Unfortunately, patients with systemic rheumatoid vasculitis may develop mononeuritis multiplex [116]. Mononeuritis in RA often begins with numbness and then progresses to tingling and muscle weakness. Initially, the mononeuritis is asymmetric but may become symmetrical. Other early manifestations of rheumatoid vasculitis include pericarditis and scleritis. Rheumatoid vasculitis is also strongly associated with the presence of rheumatoid nodules, and most RA patients with vasculitis have nodulosis [98]. Rheumatoid vasculitis may also affect the coronary arteries. In the kidney, renal artery involvement, as occurs in polyarteritis nodosa with vasculitis, may cause renal failure, although the disorder should be distinct from polyarteritis nodosa [117, 118].

Rheumatoid vasculitis is an unusual complication of RA, which has profound impact on disease severity and life expectancy of patients who develop this extraarticular disease manifestation.

\subsection{Angiogenesis in RA}

RA is the rheumatic disease in which the role of angiogenesis has been studied most extensively; it is characterized by excessive angiogenesis [119]. Proangiogenic mediators associated with RA include the following: growth factors such as VEGF; cytokines such as TNF- $\alpha$ (which has many effects in addition to angiogenesis); chemokines such as IL-8; and other mediators, including ET-1. VEGF, an endothelial selective mitogen that is secreted predominantly by macrophages, is an important cytokine in both angiogenesis and vasculogenesis [120]. In RA, VEGF expression is induced by hypoxia. Hypoxic environment of the inflamed RA joint activates the VEGF gene via binding of hypoxia inducible factor. This in turn augments IL-1 or transforming growth factor (TGF)- $\beta$ induced synovial fibroblast VEGF [121], which contributes significantly to angiogenesis in the synovium and progression of RA. Evidence of the importance of TNF- $\alpha$ as a proangiogenic mediator in RA is illustrated by the effect of giving anti-TNF-a to patients with RA. Administration of anti-TNF- $\alpha$ drugs to patients with RA leads to vascular deactivation, including decreased angiogenesis and endothelial cell markers [122]. Chemokines are also very important in angiogenesis in RA. Recent studies have shown that the chemokine IL-8/CXC chemokine ligand (CXCL) 8 plays a role in the pathogenesis of RA synovitis. This molecule is angiogenic and appears to be responsible for much of the macrophage-derived angiogenic activity seen in RA [123]. In addition to its well recognized effects as a potent endogenous vasoconstrictor and smooth muscle mitogen, ET- 1 also appears to have proangiogenic effects in some rheumatic diseases. In patients with RA, levels of ET-1 in synovial fluid, serum and plasma are elevated in comparison with those in normal individuals [124-127]. Although this clearly does not demonstrate a causal role for ET-1 in the pathophysiology of RA, it may suggest some degree of involvement. 


\subsection{Vasculopathy in RA}

Atherogenesis is a precocious feature in RA, as extraarticular manifestation of the syndrome, and might be defined as rheumatoid vasculopathy. RA has been associated with precocious and accelerated atherosclerosis [128-134] and with increased CV morbidity and mortality [135]. Notably, atherosclerosis has been proposed as extraarticular manifestation of the disease [130]. Several disease-related mechanisms may be involved in the development of premature vascular damage in RA, including increased synthesis of proinflammatory mediators (such as cytokines, chemokines, adhesion molecules), autoantibodies against endothelial cell components, perturbations in T-cell subsets, genetic polymorphisms, hyperhomocysteinemia, oxidative stress, and abnormal vascular repair, as well as iatrogenic factors [136, 137]. Hyperhomocysteinemia, which is a common finding in patients with RA, is a further contributor to the impaired endothelial function, potentiates the oxidation of lipoproteins, and has prothrombotic effects [138]. Inflammation severity was found to be associated with functional and structural arterial wall changes in patients with recent RA onset, and early control of inflammation is associated with improved arterial function that may reduce atherosclerosis progression [139].

\section{Conclusion}

Vascular damage in humans develops on various grounds. It may be inflammatory or noninflammatory. The damages may be induced by environmental factors (toxic agents, medications, microorganisms), through cancer as a paraneoplastic syndrome, or may be directly associated with an active immune process. Distinguishing between noninflammatory vasculopathy and vasculitis can pose a significant diagnostic challenge in the absence of histological examination. Vasculitis should not be confused with vasculopathy, which simply means something is wrong with the blood vessels, although it's usually not vasculitis. When a blood vessel becomes inflamed and narrowed, blood supply to that area can become partially or completely blocked. Complete blockage is called occlusion; it causes the vessel wall to swell and makes things stick to the wall -- so a clot forms. When vasculitis interferes with circulation in any part of the body, it causes local tenderness and pain. If the blood vessels are close to the skin, characteristic rashes occur. Depending on where the blockage occurs, almost any organ in the body can be affected. However, vasculopathy can also block blood vessels, but it does not cause the fever, pain, and local tenderness associated with vasculitis.

As this chapter illustrates, vascular involvement is an important part in the RA, SLE and SSc pathogenesis. Vasculitis in RA is generally associated with longstanding disease, has an important impact on s patient's well being and markedly influences patient life expectancy. Predictors of vasculitis in RA patients include clinical and genetic factors. Vaculitis in RA generally affects small and medium-seized vessels. It shares many characteristics with a classic polyarteritis nodosa and may affect peripheral nerves, causing mononeuritis multiplex, skin, gastrointestinal tract and other organs. It is not usually associated with the development of microaneurysms. Atherogenesis is a precocious feature in RA, as extraarticular manifestation 
of the syndrome, and might be defined as rheumatoid vasculopathy. Several disease-related mechanisms may be involved in the development of premature vascular damage in RA. Increased synthesis of proinflammatory mediators, autoantibodies against endothelial cell components, perturbations in T-cell subsets, genetic polymorphisms, hyperhomocysteinemia, oxidative stress and abnormal vascular repair are associated with atherosclerosis in RA.

Vascular involvement in SLE may be of inflammatory or thrombotic origin. Both mechanisms involve the immune system. The activation and consequent endothelial lesions play a very important role in the disease pathogenesis. The common hypothesis for vasculopathy in SLE concerns the endothelial deposition of circulating immune complexes. There are many various autoantibodies in SLE as circulating immune complexes which directly or indirectly affect endothelial cells, causing chronic vessel wall damage. Furthermore, vasculitis in SLE is proatherogenic condition and is characterized by leucocytes activation and production of cytokine and other inflammatory mediators.

Although SSc is considered a fibrosing disease, vascular involvement plays a major role in pathogenesis and organ dysfunction. SSc vascular disease involves vasculopathy with luminal occlusion, thrombosis and vasospasm. The vascular pathology in SSc is not necessarily an inflammatory process and would be better be characterised as a vasculopathy in the absence of vasculitis. In the current pathogenic model of SSc, a vascular injury of unknown cause leads to endothelial apoptosis and initiates the process of SSc vasculopathy. Histopathology of SSc vasculopathy reflects the underlying pathogenesis, with myofibroblast proliferation and matrix deposit in the subendothelial layer leading to obliterative thickening of vessel walls. Inflammatory infiltrates are absent, and the internal elastic lamina remains intact. In contrast to vasculopathy, concurrent vasculitis in SSc shows histopathological evidence of inflammation with presence of mononuclear infiltrates and destruction of the vascular wall.

\section{Author details}

Mislav Radić ${ }^{1}$ and Josipa Radić ${ }^{2}$

1 Division of Rheumatology and Clinical Immunology, University Hospital Centre Split, University of Split School of Medicine, Split, Croatia

2 Division of Nephrology, University Hospital Centre Split, University of Split School of Medicine, Split, Croatia

\section{References}

[1] Medsger, T. A. Jr. Natural history of systemic sclerosis and the assessment of disease activity, severity, functional status, and psychologic well-being. Rheumatic diseases clinics of North America. (2003). , 29(2), 255-73. 
[2] LeRoy ECSystemic sclerosis. A vascular perspective. Rheumatic diseases clinics of North America. (1996). , 22(4), 675-94.

[3] Maricq, H. R. Capillary abnormalities, Raynaud's phenomenon, and systemic sclerosis in patients with localized scleroderma. Archives of dermatology. (1992). , 128(5), 630-2.

[4] Carpentier, P. H, Satger, B, Poensin, D, \& Maricq, H. R. Incidence and natural history of Raynaud phenomenon: A long-term follow-up (14 years) of a random sample from the general population. Journal of vascular surgery : official publication, the Society for Vascular Surgery [and] International Society for Cardiovascular Surgery, North American Chapter. (2006). , 44(5), 1023-8.

[5] Ebert, E. C. Gastric and enteric involvement in progressive systemic sclerosis. Journal of clinical gastroenterology. (2008). , 42(1), 5-12.

[6] Kahaleh, B. Vascular disease in scleroderma: mechanisms of vascular injury. Rheumatic diseases clinics of North America. (2008). , 34(1), 57-71.

[7] Fleming, J. N, Nash, R. A, \& Mahoney, W. M. Jr., Schwartz SM. Is scleroderma a vasculopathy? Current rheumatology reports. (2009). , 11(2), 103-10.

[8] Muller-ladner, U, Distler, O, Ibba-manneschi, L, Neumann, E, \& Gay, S. Mechanisms of vascular damage in systemic sclerosis. Autoimmunity. (2009). , 42(7), 587-95.

[9] Mulligan-kehoe, M. J, \& Simons, M. Vascular disease in scleroderma: angiogenesis and vascular repair. Rheumatic diseases clinics of North America. (2008). , 34(1), 73-9.

[10] Wigley, F. M. Vascular disease in scleroderma. Clinical reviews in allergy \& immunology. (2009).

[11] Dangelo, W. A, Fries, J. F, Masi, A. T, \& Shulman, L. E. Pathologic Observations in Systemic Sclerosis (Scleroderma)- a Study of 58 Autopsy Cases and 58 Matched Controls. American Journal of Medicine. (1969). , 46(3), 428-9.

[12] Nagy, Z, \& Czirjak, L. Nailfold digital capillaroscopy in 447 patients with connective tissue disease and Raynaud's disease. Journal of the European Academy of Dermatology and Venereology : JEADV. (2004). , 18(1), $62-8$.

[13] Birkenhager, R, Schneppe, B, Rockl, W, Wilting, J, Weich, H. A, \& Mccarthy, J. E. Synthesis and physiological activity of heterodimers comprising different splice forms of vascular endothelial growth factor and placenta growth factor. The Biochemical journal. (1996). Pt 3):703-7.

[14] Distler, O, Distler, J. H, Scheid, A, Acker, T, Hirth, A, Rethage, J, et al. Uncontrolled expression of vascular endothelial growth factor and its receptors leads to insufficient skin angiogenesis in patients with systemic sclerosis. Circulation research. (2004). , 95(1), 109-16. 
[15] Mulligan-kehoe, M. J, Drinane, M. C, Mollmark, J, Casciola-rosen, L, Hummers, L. K, Hall, A, et al. Antiangiogenic plasma activity in patients with systemic sclerosis. Arthritis Rheum. (2007). , 56(10), 3448-58.

[16] Jun, J. B, Kuechle, M, Harlan, J. M, \& Elkon, K. B. Fibroblast and endothelial apoptosis in systemic sclerosis. Current opinion in rheumatology. (2003). Epub 2003/10/22., 15(6), 756-60.

[17] Horstmeyer, A, Licht, C, Scherr, G, Eckes, B, \& Krieg, T. Signalling and regulation of collagen I synthesis by ET-1 and TGF-beta1. The FEBS journal. (2005). , 272(24), 6297-309.

[18] Shi-wen, X, Denton, C. P, Dashwood, M. R, Holmes, A. M, Bou-gharios, G, Pearson, $\mathrm{J}$. D, et al. Fibroblast matrix gene expression and connective tissue remodeling: role of endothelin-1. The Journal of investigative dermatology. (2001). , 116(3), 417-25.

[19] Shephard, P, Hinz, B, Smola-hess, S, Meister, J. J, Krieg, T, \& Smola, H. Dissecting the roles of endothelin, TGF-beta and GM-CSF on myofibroblast differentiation by keratinocytes. Thrombosis and haemostasis. (2004). , 92(2), 262-74.

[20] Vancheeswaran, R, Magoulas, T, Efrat, G, Wheeler-jones, C, Olsen, I, Penny, R, et al. Circulating endothelin-1 levels in systemic sclerosis subsets--a marker of fibrosis or vascular dysfunction? The Journal of rheumatology. (1994). , 21(10), 1838-44.

[21] Korn, J. H, Mayes, M, Cerinic, M. M, Rainisio, M, Pope, J, Hachulla, E, et al. Digital ulcers in systemic sclerosis- Prevention by treatment with bosentan, an oral endothelin receptor antagonist. Arthritis Rheum-Us. (2004). , 50(12), 3985-93.

[22] Kuhn, A, Haust, M, Ruland, V, Weber, R, Verde, P, Felder, G, et al. Effect of bosentan on skin fibrosis in patients with systemic sclerosis: a prospective, open-label, noncomparative trial. Rheumatology. (2010). , 49(7), 1336-45.

[23] Hirata, Y, Emori, T, Eguchi, S, Kanno, K, Imai, T, Ohta, K, et al. Endothelin Receptor Subtype-B Mediates Synthesis of Nitric-Oxide by Cultured Bovine Endothelial-Cells. J Clin Invest. (1993). , 91(4), 1367-73.

[24] Yamamoto, T, Katayama, I, \& Nishioka, K. Nitric oxide production and inducible nitric oxide synthase expression in systemic sclerosis. Journal of Rheumatology. (1998). , 25(2), 314-7.

[25] Takagi, K, Kawaguchi, Y, Hara, M, Sugiura, T, Harigai, M, \& Kamatani, N. Serum nitric oxide (NO) levels in systemic sclerosis patients: correlation between NO levels and clinical features. Clin Exp Immunol. (2003). , 134(3), 538-44.

[26] Beyer, C, Schett, G, Gay, S, \& Distler, O. Distler JHW. Hypoxia Hypoxia in the pathogenesis of systemic sclerosis. Arthritis research \& therapy. (2009). 
[27] Herrick, A. L, Oogarah, P. K, Freemont, A. J, Marcuson, R, \& Haeney, M. Jayson MIV. Vasculitis in Patients with Systemic-Sclerosis and Severe Digital Ischemia Requiring Amputation. Ann Rheum Dis. (1994). , 53(5), 323-6.

[28] Hunder, G. G, Bloch, D. A, Michel, B. A, Stevens, M. B, Arend, W. P, Calabrese, L. H, et al. The American-College-of-Rheumatology 1990 Criteria for the Classification of Giant-Cell Arteritis. Arthritis Rheum-Us. (1990). , 33(8), 1122-8.

[29] Perezjimenez, F, Lopezrubio, F, Canadillas, F, Jimenezalonso, J, \& Jimenezpereperez, J. Giant-Cell Arteritis Associated with Progressive Systemic-Sclerosis. Arthritis Rheum-Us. (1982). , 25(6), 717-8.

[30] Hupp, S. L. Giant-Cell Arteritis Associated with Progressive Systemic-Sclerosis. J Clin Neuro-Ophthal. (1989). , 9(2), 126-30.

[31] Sari-kouzel, H, Herrick, A. L, Freemont, A. J, Marcuson, R. W, \& Jayson, M. I. Giant cell arteritis in a patient with limited cutaneous systemic sclerosis. Rheumatology. (1999). , 38(5), 479-80.

[32] Reinhold-keller, E, Herlyn, K, Wagner-bastmeyer, R, \& Gross, W. L. Stable incidence of primary systemic vasculitides over five years: Results from the German vasculitis register. Arthrit Rheum-Arthr. (2005). , 53(1), 93-9.

[33] Seyahi, E, Ugurlu, S, Cumali, R, Balci, H, Seyahi, N, Yurdakul, S, et al. Atherosclerosis in Takayasu arteritis. Ann Rheum Dis. (2006). , 65(9), 1202-7.

[34] Arend, W. P, Michel, B. A, Bloch, D. A, Hunder, G. G, Calabrese, L. H, Edworthy, S. $\mathrm{M}$, et al. The American-College-of-Rheumatology 1990 Criteria for the Classification of Takayasu Arteritis. Arthritis Rheum-Us. (1990). , 33(8), 1129-34.

[35] Passiu, G, Vacca, A, Sanna, G, Cauli, A, Laudadio, M, Garau, P, et al. Takayasu's arteritis overlapping with systemic sclerosis. Clinical and experimental rheumatology. (1999). , 17(3), 363-5.

[36] Yago, T, Ota, S, \& Nishinarita, M. A case of systemic sclerosis complicated by Takayasu's arteritis]. Ryumachi [Rheumatism]. (2002). , 42(3), 605-9.

[37] Kocabay, G, Tiryaki, B, Ekmekci, A, \& Inanc, M. Takayasu arteritis associated with systemic sclerosis. Modern rheumatology / the Japan Rheumatism Association. (2006). , 16(2), 120-1.

[38] Kim, T. J, Uhm, W. S, Song, S. Y, \& Jun, J. B. Unilateral weak radial pulse in a patient with systemic sclerosis: Takayasu's arteritis or thoracic outlet syndrome? Rheumatology international. (2007). Epub 2006/12/23., 27(8), 789-90.

[39] Lightfoot, R. W. Jr., Michel BA, Bloch DA, Hunder GG, Zvaifler NJ, McShane DJ, et al. The American College of Rheumatology 1990 criteria for the classification of polyarteritis nodosa. Arthritis Rheum. (1990). , 33(8), 1088-93.

[40] Pagnoux, C, Seror, R, Henegar, C, Mahr, A, \& Cohen, P. Le Guern V, et al. Clinical features and outcomes in 348 patients with polyarteritis nodosa: a systematic retro- 
spective study of patients diagnosed between 1963 and 2005 and entered into the French Vasculitis Study Group Database. Arthritis Rheum. (2010). , 62(2), 616-26.

[41] Kang, M. S, Park, J. H, \& Lee, C. W. A case of overlap between systemic sclerosis and cutaneous polyarteritis nodosa. Clin Exp Dermatol. (2008). , 33(6), 781-3.

[42] Calabrese, L. H, Duna, G. F, \& Lie, J. T. Vasculitis in the central nervous system. Arthritis Rheum-Us. (1997). , 40(7), 1189-201.

[43] Lie, J. T. Primary (granulomatous) angiitis of the central nervous system: a clinicopathologic analysis of 15 new cases and a review of the literature. Human pathology. (1992). , 23(2), 164-71.

[44] Calabrese, L. H, \& Mallek, J. A. Primary angiitis of the central nervous system. Report of 8 new cases, review of the literature, and proposal for diagnostic criteria. Medicine. (1988). , 67(1), 20-39.

[45] Brouet, J. C, Clauvel, J. P, Danon, F, Klein, M, \& Seligmann, M. Biologic and clinical significance of cryoglobulins. A report of 86 cases. The American journal of medicine. (1974). , 57(5), 775-88.

[46] Jantunen, E, Soppi, E, Neittaanmaki, H, \& Lahtinen, R. Essential cryofibrinogenaemia, leukocytoclastic vasculitis and chronic purpura. Journal of internal medicine. (1993). , 234(3), 331-3.

[47] Blain, H, Cacoub, P, Musset, L, Costedoat-chalumeau, N, Silberstein, C, Chosidow, O, et al. Cryofibrinogenaemia: a study of 49 patients. Clin Exp Immunol. (2000). , 120(2), 253-60.

[48] Husson, J. M, Druet, P, Contet, A, Fiessinger, J. N, \& Camilleri, J. P. Systemic sclerosis and cryoglobulinemia. Clinical immunology and immunopathology. (1976). , 6(1), 77-82.

[49] Barrett, M. C, Prendiville, J. S, Pardy, B. J, \& Cream, J. J. Cryofibrinogenaemia and acute gangrene in systemic sclerosis. Postgraduate medical journal. (1986). , 62(732), 935-6.

[50] Yurdakul, S, Hamuryudan, V, \& Yazici, H. Behcet syndrome. Current opinion in rheumatology. (2004). , 16(1), 38-42.

[51] Criteria for diagnosis of Behcet's diseaseInternational Study Group for Behcet's Disease. Lancet. (1990). , 335(8697), 1078-80.

[52] Choy, E, Kingsley, G, \& Panayi, G. Systemic sclerosis occurring in a patient with Adamantiades-Behcet's disease. Br J Rheumatol. (1993). , 32(2), 160-1.

[53] Yokota, K, Hirano, M, Akiba, H, Adachi, D, Takeishi, M, Akiyama, Y, et al. A case of Behcet's disease with esophageal ulcers complicated with systemic sclerosis, chronic hepatitis C, and pancytopenia]. Nihon Rinsho Men'eki Gakkai kaishi = Japanese journal of clinical immunology. (2004). , 27(3), 164-70. 
[54] Mcadam, L. P, Hanlan, O, Bluestone, M. A, \& Pearson, R. CM. Relapsing polychondritis: prospective study of 23 patients and a review of the literature. Medicine. (1976). , 55(3), 193-215.

[55] Damiani, J. M, \& Levine, H. L. Relapsing polychondritis--report of ten cases. The Laryngoscope. (1979). Pt 1):929-46.

[56] Sugisaki, K, Takeda, I, Kanno, T, \& Kasukawa, R. A case report of relapsing polychondritis with an auricular ulcer complicated by systemic sclerosis]. Ryumachi [Rheumatism]. (2002). , 42(3), 610-7.

[57] Holle, J. U, \& Gross, W. L. ANCA-associated vasculitides: pathogenetic aspects and current evidence-based therapy. Journal of autoimmunity. (2009).

[58] Rho, Y. H, Choi, S. J, Lee, Y. H, Ji, J. D, \& Song, G. G. Scleroderma associated with ANCA-associated vasculitis. Rheumatology international. (2006). , 26(5), 465-8.

[59] Cruz, D. D. Vasculitis in systemic lupus erythematosus. Lupus. (1998). , 7(4), 270-4.

[60] Criado, P. R, Rivitti, E. A, Sotto, M. N, Valente, N. Y, Aoki, V, Carvalho, J. F, et al. Livedoid vasculopathy: an intringuing cutaneous disease. Anais brasileiros de dermatologia. (2011). , 86(5), 961-77.

[61] Sopena, B, Perez-rodriguez, M. T, Rivera, A, Ortiz-rey, J. A, Lamas, J, \& Freire-dapena, M. C. Livedoid vasculopathy and recurrent thrombosis in a patient with lupus: seronegative antiphospholipid syndrome? Lupus. (2010). , 19(11), 1340-3.

[62] Shimizu, A, Tamura, A, Yamanaka, M, Amano, H, Nagai, Y, \& Ishikawa, O. Case of livedoid vasculopathy with extensive dermal capillary thrombi. The Journal of dermatology. (2010). , 37(1), 94-7.

[63] Khenifer, S, Thomas, L, Balme, B, \& Dalle, S. Livedoid vasculopathy: thrombotic or inflammatory disease? Clin Exp Dermatol. (2010). , 35(7), 693-8.

[64] Sen, D, \& Isenberg, D. A. Antineutrophil cytoplasmic autoantibodies in systemic lupus erythematosus. Lupus. (2003). , 12(9), 651-8.

[65] Sung, J. M, Hsu, S. C, Chen, F. F, \& Huang, J. J. Systemic lupus erythematosus presented as non-inflammatory necrotizing vasculopathy-induced ischemic glomerulopathy and small vessels-related ischemic cardiomyopathy. Lupus. (2002). , 11(7), 458-62.

[66] Appel, G. B, Pirani, C. L, \& Dagati, V. Renal Vascular Complications of Systemic Lupus-Erythematosus. Journal of the American Society of Nephrology. (1994). , 4(8), 1499-515.

[67] Jayne, D. The clinical features and pathology of vasculitis associated with anti-myeloperoxidase autoantibodies. Japanese journal of infectious diseases. (2004). S, 16-7. 
[68] Romero-diaz, J, Vargas-vorackova, F, Kimura-hayama, E, Cortazar-benitez, L. F, Gijon-mitre, R, Criales, $\mathrm{S}$, et al. Systemic lupus erythematosus risk factors for coronary artery calcifications. Rheumatology (Oxford). (2012). , 51(1), 110-9.

[69] Burgos, P. I, \& Mcgwin, G. Jr., Reveille JD, Vila LM, Alarcon GS. Factors predictive of thrombotic events in LUMINA, a multi-ethnic cohort of SLE patients (LXXII). Rheumatology (Oxford). (2010). , 49(9), 1720-5.

[70] Carlson, J, \& Chen, K. R. Cutaneous vasculitis update: Neutrophilic muscular vessel and eosinophilic, granulomatous, and lymphocytic vasculitis syndromes. Am J Dermatopath. (2007). , 29(1), 32-43.

[71] Carlson, J. A, \& Chen, K. R. Cutaneous vasculitis update: Small vessel neutrophilic vasculitis syndromes. Am J Dermatopath. (2006). , 28(6), 486-506.

[72] Sunderkotter, C, Bonsmann, G, Sindrilaru, A, \& Luger, T. Management of leukocytoclastic vasculitis. J Dermatol Treat. (2005). , 16(4), 193-206.

[73] Carlson, J. A, Cavaliere, L. F, \& Grant-kels, J. M. Cutaneous vasculitis: diagnosis and management. Clin Dermatol. (2006). , 24(5), 414-29.

[74] Kallenberg CGMHeeringa P. Pathogenesis of vasculitis. Lupus. (1998). , 7(4), 280-4.

[75] Calamia, K. T, \& Balabanova, M. Vasculitis in systemic lupus erythematosis. Clin Dermatol. (2004). , 22(2), 148-56.

[76] Zecevic, R. D, Vojvodic, D, Ristic, B, Pavlovic, M. D, Stefanovic, D, \& Karadaglic, D. Skin lesions--an indicator of disease activity in systemic lupus erythematosus? Lupus. (2001). , 10(5), 364-7.

[77] Meroni, P. L, Tincani, A, Sepp, N, Raschi, E, Testoni, C, Corsini, E, et al. Endothelium and the brain in CNS lupus. Lupus. (2003). , 12(12), 919-28.

[78] Rodriguez-garcia, J. L, Bertolaccini, M. L, Cuadrado, M. J, Sanna, G, Ateka-barrutia, O, \& Khamashta, M. A. Clinical manifestations of antiphospholipid syndrome (APS) with and without antiphospholipid antibodies (the so-called'seronegative APS'). Ann Rheum Dis. (2012). , 71(2), 242-4.

[79] Tenedios, F, Erkan, D, \& Lockshin, M. D. Cardiac involvement in the antiphospholipid syndrome. Lupus. (2005). , 14(9), 691-6.

[80] Frostegard, J. Systemic lupus erythematosus and cardiovascular disease. Lupus. (2008). , 17(5), 364-7.

[81] Pyrpasopoulou, A, Triantafyllou, A, Anyfanti, P, Douma, S, \& Aslanidis, S. Capillaroscopy as a screening test for clinical antiphospholipid syndrome. Eur J Intern Med. (2011). EE9., 158.

[82] Cieslik, P, Hrycek, A, \& Klucinski, P. Vasculopathy and vasculitis in systemic lupus erythematosus. Polskie Archiwum Medycyny Wewnetrznej. (2008). 
[83] Guilpain, P, \& Mouthon, L. Antiendothelial cells autoantibodies in vasculitis-associated systemic diseases. Clinical reviews in allergy \& immunology. (2008).

[84] Praprotnik, S, Blank, M, Meroni, P. L, Rozman, B, Eldor, A, \& Shoenfeld, Y. Classification of anti-endothelial cell antibodies into antibodies against microvascular and macrovascular endothelial cells- The pathogenic and diagnostic implications. Arthritis Rheum-Us. (2001). , 44(7), 1484-94.

[85] Dobre, M, Wish, J, \& Negrea, L. Hydralazine-Induced ANCA-Positive Pauci-immune Glomerulonephritis: A Case Report and Literature Review. Renal Failure. (2009). , 31(8), 745-8.

[86] Avcin, T, Canova, M, Guilpain, P, \& Guillevin, L. Kallenberg CGM, Tincani A, et al. Infections, connective tissue diseases and vasculitis. Clinical and experimental rheumatology. (2008). SS26., 18.

[87] Radic, M. Martinovic Kaliterna D, Radic J. Drug-induced vasculitis: a clinical and pathological review. The Netherlands journal of medicine. (2012). , 70(1), 12-7.

[88] Ramos-casals, M, \& Font, J. Mycophenolate mofetil in patients with hepatitis C virus infection. Lupus. (2005). SS72., 64.

[89] Erhardt, C. C, Mumford, P. A, Venables, P. J, \& Maini, R. N. Factors predicting a poor life prognosis in rheumatoid arthritis: an eight year prospective study. Annals of the rheumatic diseases. (1989). , 48(1), 7-13.

[90] Puechal, X, Said, G, Hilliquin, P, Coste, J, Job-deslandre, C, Lacroix, C, et al. Peripheral neuropathy with necrotizing vasculitis in rheumatoid arthritis. A clinicopathologic and prognostic study of thirty-two patients. Arthritis and rheumatism. (1995). , 38(11), 1618-29.

[91] Scott, D. G, Bacon, P. A, \& Tribe, C. R. Systemic rheumatoid vasculitis: a clinical and laboratory study of 50 cases. Medicine. (1981). , 60(4), 288-97.

[92] Pagnoux, C, Mahr, A, Cohen, P, \& Guillevin, L. Presentation and outcome of gastrointestinal involvement in systemic necrotizing vasculitides: analysis of 62 patients with polyarteritis nodosa, microscopic polyangiitis, Wegener granulomatosis, ChurgStrauss syndrome, or rheumatoid arthritis-associated vasculitis. Medicine. (2005). , $84(2), 115-28$.

[93] Scott DGIBacon PA, Allen C, Elson CJ, Wallington T. Igg Rheumatoid-Factor, Complement and Immune-Complexes in Rheumatoid Synovitis and Vasculitis- Comparative and Serial Studies during Cyto-Toxic Therapy. Clin Exp Immunol. (1981). , 43(1), 54-63.

[94] Turesson, C, Jacobsson, L. T, Sturfelt, G, Matteson, E. L, Mathsson, L, \& Ronnelid, J. Rheumatoid factor and antibodies to cyclic citrullinated peptides are associated with severe extra-articular manifestations in rheumatoid arthritis. Annals of the rheumatic diseases. (2007). , 66(1), 59-64. 
[95] Watts, R. A, Carruthers, D. M, Symmons, D. P, \& Scott, D. G. The incidence of rheumatoid vasculitis in the Norwich Health Authority. British journal of rheumatology. (1994). , 33(9), 832-3.

[96] Turesson, C, Fallon, O, Crowson, W. M, Gabriel, C. S, Matteson, S. E, \& Extra-articular, E. L. disease manifestations in rheumatoid arthritis: incidence trends and risk factors over 46 years. Annals of the rheumatic diseases. (2003). , 62(8), 722-7.

[97] Voskuyl, A. E, Zwinderman, A. H, Westedt, M. L, Vandenbroucke, J. P, Breedveld, F. C, \& Hazes, J. M. Factors associated with the development of vasculitis in rheumatoid arthritis: results of a case-control study. Annals of the rheumatic diseases. (1996). , 55(3), 190-2.

[98] Turesson, C, Mcclelland, R. L, Christianson, T, \& Matteson, E. Clustering of extraarticular manifestations in patients with rheumatoid arthritis. The Journal of rheumatology. (2008). , 35(1), 179-80.

[99] Struthers, G. R, Scott, D. L, Delamere, J. P, Sheppeard, H, \& Kitt, M. Smoking and rheumatoid vasculitis. Rheumatology international. (1981). , 1(3), 145-6.

[100] Turesson, C, Schaid, D. J, Weyand, C. M, Jacobsson, L. T, Goronzy, J. J, Petersson, I. F, et al. Association of HLA-C3 and smoking with vasculitis in patients with rheumatoid arthritis. Arthritis and rheumatism. (2006). , 54(9), 2776-83.

[101] Weyand, C. M, Xie, C, \& Goronzy, J. J. Homozygosity for the HLA-DRB1 allele selects for extraarticular manifestations in rheumatoid arthritis. The Journal of clinical investigation. (1992). , 89(6), 2033-9.

[102] Turesson, C, Schaid, D. J, Weyand, C. M, Jacobsson, L. T, Goronzy, J. J, Petersson, I. F, et al. The impact of HLA-DRB1 genes on extra-articular disease manifestations in rheumatoid arthritis. Arthritis research \& therapy. (2005). R, 1386-93.

[103] Yen, J. H, Moore, B. E, Nakajima, T, Scholl, D, Schaid, D. J, Weyand, C. M, et al. Major histocompatibility complex class I-recognizing receptors are disease risk genes in rheumatoid arthritis. J Exp Med. (2001). , 193(10), 1159-67.

[104] Silman, A. J, \& Newman, J. MacGregor AJ. Cigarette smoking increases the risk of rheumatoid arthritis- Results from a nationwide study of disease-discordant twins. Arthritis and rheumatism. (1996). , 39(5), 732-5.

[105] Gorman, J. D, David-vaudey, E, Pai, M, Lum, R. F, \& Criswell, L. A. Particular HLADRB1 shared epitope genotypes are strongly associated with rheumatoid vasculitis. Arthritis and rheumatism. (2004). , 50(11), 3476-84.

[106] Turesson, C, Fallon, O, Crowson, W. M, Gabriel, C. S, \& Matteson, S. E. EL. Occurrence of extraarticular disease manifestations is associated with excess mortality in a community based cohort of patients with rheumatoid arthritis. Journal of Rheumatology. (2002). , 29(1), 62-7. 
[107] Maradit-kremers, H, Nicola, P. J, Crowson, C. S, Ballman, K. V, \& Gabriel, S. E. Cardiovascular death in rheumatoid arthritis: a population-based study. Arthritis and rheumatism. (2005). , 52(3), 722-32.

[108] Turesson, C, Mcclelland, R. L, Christianson, T. J, \& Matteson, E. L. Severe extra-articular disease manifestations are associated with an increased risk of first ever cardiovascular events in patients with rheumatoid arthritis. Annals of the rheumatic diseases. (2007). , 66(1), 70-5.

[109] Doran, M. F, Crowson, C. S, Pond, G. R, Fallon, O, \& Gabriel, W. M. SE. Predictors of infection in rheumatoid arthritis. Arthritis and rheumatism. (2002). , 46(9), 2294-300.

[110] Iyngkaran, P, Limaye, V, Hill, C, Henderson, D, Pile, K. D, \& Rischmueller, M. Rheumatoid vasculitis following influenza vaccination. Rheumatology (Oxford). (2003). , 42(7), 907-9.

[111] Watts, R. A, Carruthers, D. M, \& Scott, D. G. Isolated nail fold vasculitis in rheumatoid arthritis. Annals of the rheumatic diseases. (1995). , 54(11), 927-9.

[112] Jorizzo, J. L, \& Daniels, J. C. Dermatologic conditions reported in patients with rheumatoid arthritis. Journal of the American Academy of Dermatology. (1983). , 8(4), 439-57.

[113] Geirsson, A. J, Sturfelt, G, \& Truedsson, L. Clinical and serological features of severe vasculitis in rheumatoid arthritis: prognostic implications. Annals of the rheumatic diseases. (1987). , 46(10), 727-33.

[114] Achkar, A. A, Stanson, A. W, Johnson, M, Srivatsa, S. S, Dale, L. C, \& Weyand, C. M. Rheumatoid Vasculitis Manifesting as Intraabdominal Hemorrhage. Mayo Clin Proc. (1995). , 70(6), 565-9.

[115] Bywaters EGLPeripheral Vascular Obstruction in Rheumatoid Arthritis and Its Relationship to Other Vascular Lesions. Annals of the rheumatic diseases. (1957). , 16(1), 84-103.

[116] Said, G, \& Lacroix, C. Primary and secondary vasculitic neuropathy. J Neurol. (2005). , 252(6), 633-41.

[117] Boers, M, \& Croonen, A. M. Dijkmans BAC, Breedveld FC, Eulderink F, Cats A, et al. Renal Findings in Rheumatoid-Arthritis- Clinical Aspects of 132 Necropsies. Annals of the rheumatic diseases. (1987). , 46(9), 658-63.

[118] Ball, J. Rheumatoid Arthritis and Polyarteritis Nodosa. Annals of the rheumatic diseases. (1954). , 13(4), 277-90.

[119] Koch, A. E. The role of angiogenesis in rheumatoid arthritis: recent developments. Annals of the rheumatic diseases. (2000). , 59, 65-71. 
[120] Koch, A. E, Harlow, L. A, Haines, G. K, Amento, E. P, Unemori, E. N, Wong, W. L, et al. Vascular Endothelial Growth-Factor- a Cytokine Modulating Endothelial Function in Rheumatoid-Arthritis. J Immunol. (1994). , 152(8), 4149-56.

[121] Cho, M. L, Cho, C. S, Min, S. Y, Kim, S. H, Lee, S. S, Kim, W. U, et al. Cyclosporine inhibition of vascular endothelial growth factor production in rheumatoid synovial fibroblasts. Arthritis and rheumatism. (2002). , 46(5), 1202-9.

[122] Paleolog, E. M, Young, S, Stark, A. C, Mccloskey, R. V, Feldmann, M, \& Maini, R. N. Modulation of angiogenic vascular endothelial growth factor by tumor necrosis factor alpha and interleukin-1 in rheumatoid arthritis. Arthritis and rheumatism. (1998). , 41(7), 1258-65.

[123] Koch, A. E, Polverini, P. J, Kunkel, S. L, Harlow, L. A, Dipietro, L. A, Elner, V. M, et al. Interleukin-8 as a Macrophage-Derived Mediator of Angiogenesis. Science. (1992). , 258(5089), 1798-801.

[124] Haq, A, Ramahi, K, Al-dalaan, A, \& Al-sedairy, S. T. Serum and synovial fluid concentrations of endothelin-1 in patients with rheumatoid arthritis. J Med. (1999).

[125] Miyasaka, N, Hirata, Y, Ando, K, Sato, K, Morita, H, Shichiri, M, et al. Increased Production of Endothelin-1 in Patients with Inflammatory Arthritides. Arthritis and rheumatism. (1992). , 35(4), 397-400.

[126] Pache, M, Kaiser, H. J, Haufschild, T, Lubeck, P, \& Flammer, J. Increased endothelin-1 plasma levels in giant cell arteritis: A report on four patients. Am J Ophthalmol. (2002). , 133(1), 160-2.

[127] Nahir, A. M, Hoffman, A, Lorber, M, \& Keiser, H. R. Presence of Immunoreactive Endothelin in Synovial-Fluid- Analysis of 22 Cases. Journal of Rheumatology. (1991). , 18(5), 678-80.

[128] Jonsson, S. W, Backman, C, Johnson, O, Karp, K, Lundstrom, E, Sundqvist, K. G, et al. Increased prevalence of atherosclerosis in patients with medium term rheumatoid arthritis. Journal of Rheumatology. (2001). , 28(12), 2597-602.

[129] Kumeda, Y, Inaba, M, Goto, H, Nagata, M, Henmi, Y, Furumitsu, Y, et al. Increased thickness of the arterial intima-media detected by ultrasonography in patients with rheumatoid arthritis. Arthritis and rheumatism. (2002). , 46(6), 1489-97.

[130] Van Doornum, S, Mccoll, G, \& Wicks, I. P. Accelerated atherosclerosis- An extraarticular feature of rheumatoid arthritis? Arthritis and rheumatism. (2002). , 46(4), 862-73.

[131] Gonzalez-gay, M. A, Gonzalez-juanatey, C, \& Martin, J. Rheumatoid arthritis: A disease associated with accelerated atherogenesis. Semin Arthritis Rheu. (2005). , 35(1), $8-17$.

[132] Szekanecz, Z, \& Kerekes, G. Der H, Sandor Z, Szabo Z, Vegvari A, et al. Accelerated atherosclerosis in rheumatoid arthritis. Ann Ny Acad Sci. (2007). , 1108, 349-58. 
[133] Gerli, R, Sherer, Y, Bocci, E. B, Vaudo, G, Moscatelli, S, \& Shoenfeld, Y. Precocious atherosclerosis in rheumatoid arthritis- Role of traditional and disease-related cardiovascular risk factors. Ann Ny Acad Sci. (2007). , 1108, 372-81.

[134] Szekanecz, Z, \& Koch, A. E. Vascular involvement in rheumatic diseases:'vascular rheumatology'. Arthritis research \& therapy. (2008).

[135] Sokka, T, Abelson, B, \& Pincus, T. Mortality in rheumatoid arthritis: (2008). update. Clin Exp Rheumatol. 2008;26(5):SS61., 35.

[136] Sattar, N, Mccarey, D. W, Capell, H, \& Mcinnes, I. B. Explaining how "high-grade" systemic inflammation accelerates vascular risk in rheumatoid arthritis. Circulation. (2003). , 108(24), 2957-63.

[137] Kaplan, M. J. Management of cardiovascular disease risk in chronic inflammatory disorders. Nat Rev Rheumatol. (2009). , 5(4), 208-17.

[138] Roubenoff, R, Dellaripa, P, Nadeau, M. R, Abad, L. W, Muldoon, B. A, Selhub, J, et al. Abnormal homocysteine metabolism in rheumatoid arthritis. Arthritis and rheumatism. (1997). , 40(4), 718-22.

[139] Hannawi, S, Marwick, T. H, \& Thomas, R. Inflammation predicts accelerated brachial arterial wall changes in patients with recent-onset rheumatoid arthritis. Arthritis research \& therapy. (2009). 
